\title{
Exploration and Practice of Teaching Management Information Construction
}

\author{
Fang LIU \\ Research Department of Xijing University, Xi'an, Shaanxi, China
}

\begin{abstract}
Keywords: Teaching Management; Information Construction; College.
\end{abstract}
\begin{abstract}
The information construction of teaching management is the key factor to realize the modern management of schools. The degree of information is directly related to the quality and efficiency of running schools. At present, with the expansion of teaching scale, the task of teaching management is aggravated, and the construction of teaching management information is a new type of teaching management mode, which can effectively improve the management efficiency and management quality of teaching management personnel, and is increasingly influenced by teaching managers. It's important for the current colleges to research that how to carry out teaching management information construction.
\end{abstract}

\section{The Characteristics of Teaching Management Information Construction}

\subsection{Digitization}

Digitization is the technical basis of information management. The digital characteristics of teaching management information construction are in the process of applying computer for teaching management, combined with information technology, and present a large number of complicated teaching management information in digital form. The problems that arise in teaching management are expressed in a digital form, which makes the problem more visual and simpler. Regardless of the teachers and students in the teaching process, the digital features greatly facilitate the teaching management, improve the efficiency and quality of teaching management, and help to inspire people's thinking. In addition, the digital characteristics of teaching management information can also provide a scientific basis.

\subsection{Knowledge}

Modern society is in a society of information integration, and the means of imparting knowledge are undergoing fundamental changes. The spread of information has brought about the rapid development of the whole society. The essence of the development of information society is the process of knowledge dissemination and application. The teaching management information makes the original teaching management model face new challenges and strives to promote the improvement of teaching management. In the construction of teaching management information, the school implements the teaching management of information. Its feature is the high concentration and high sharing of information, which fully reflects the characteristics of the knowledge-based construction of teaching management information.

\subsection{Networking}

Networking refers to the use of communication technology and computer technology, will be distributed in different locations and communicate with each other according to network protocols, so that all users can share software, hardware and data resources. In the process of teaching management information construction, network is another significant feature of teaching management information.

Nowadays, computer networks are widely used in all walks of life, and the teaching management mode of colleges and universities in the information age has also undergone corresponding changes. The network in the teaching management mainly refers to the campus network, and the teaching management information construction fully integrates all the links in the teaching by using the network platform to realize the free flow and command of various teaching information, control, 
and management system interaction.

\section{The Practical Significance of Teaching Management Information Construction}

The construction of teaching management information has important practical significance, which is mainly reflected in three aspects, which are conducive to the standardization of teaching management, the fairness of teaching management and the improvement of teaching quality.

\subsection{Conducive to the standardization of teaching management}

The construction of teaching management information is a concrete manifestation of the standardization of teaching management. Generally speaking, in the teaching management, the traditional teaching management is repeatedly collected by the grassroots, which not only affects the accuracy of the teaching management data, but also wastes a lot of financial and material resources in the teaching management process, which is not conducive to the development of teaching management. In the construction of teaching management information, computer and network technology are used to collect teaching management data. Teaching management personnel at all levels perform their duties and conduct teaching management in an orderly manner, which makes teaching management personnel free from complicated and repetitive labor and improve. The management efficiency of teaching management avoids the waste of financial and material resources in teaching management, which is conducive to the standardization of teaching management.

\subsection{Conducive to the fairness of teaching management}

Teaching management information also promotes the fairness and fairness of teaching management. In the teaching management, the use of information technology, automatic optimization of the allocation of teaching resources, through the construction of high-quality digital education resources, information technology and education comprehensive deep integration, enhance the transparency of educational management, is an effective way to achieve fair teaching management. For example, the online posting and inquiry of test scores is the same for everyone. The information management of teaching management is more convenient for students' performance management. On the one hand, it improves the transparency of performance management and the fairness of teaching management; it also avoids the black-box operation of teaching managers or teachers, and thus is conducive to the maintenance of education. In addition, the construction of teaching management information, so that the school's various services, all public information is posted on the Internet, also reflects the fairness of teaching management.

\subsection{Conducive to the improvement of management quality}

In the teaching management, the information management system is more flexible and efficient, using information technology to carry out teaching management, and realize the construction of teaching management information, which is conducive to the improvement of management quality.

For the teaching management work, the teaching management information construction can improve the level and quality of teaching management to a certain extent. Teaching management in the construction of information technology, teaching

The management system can help the teaching management system to operate effectively by setting the quality and evaluation system so that teachers and students can feedback the teaching information in time.

Specifically, the majority of teachers and students put forward evaluations and opinions on the teaching management system. The teaching management work accepts the supervision and evaluation of the teachers and students, and continuously improves the teaching management system, which is conducive to the promotion of teaching management and management quality.

\section{The Problems in the Construction of Teaching Management Information}

At present, the current situation of teaching management information construction is not 
optimistic, and there are still many problems to be solved. These problems are mainly manifested in four aspects.

\subsection{Teaching management information awareness is not high}

Teaching management information is an important part of modern teaching. In the process of teaching management information construction, teaching management information awareness is not high, which is one of the problems existing in the current teaching management information construction. For the time being, in the construction of teaching management information, many colleges and universities are neglecting the importance of teaching management information in the teaching management work. In the specific teaching management work, the traditional management methods are still used for management. When transmitting information between departments, it is mainly manual work. When querying the data required for teaching, it is still customary to ask the relevant departments for data, instead of using the teaching management information system to query, so the traditional teaching management method increases the teaching management work. The workload, resulting in waste of resources and inefficiency, directly affects the efficiency of teaching management, and is not conducive to the effective development of teaching management. It is not difficult to see that the above is caused by the low awareness of teaching management information.

\subsection{Teaching management system needs to be improved}

The teaching management system still needs to be improved, which is an urgent problem that needs to be solved in the current teaching management information construction. At present, many colleges and universities have adopted an information system for teaching management, but there are still some shortcomings in the setting of teaching management system. This is due to the design of the teaching system software, mainly for the design of the problems existing in the teaching management of colleges and universities. In the specific operation process, the teaching management system does not combine the actual situation of the teaching management of the university to carry out teaching management, which makes the information construction of teaching management in colleges and universities in a difficult position. In addition, due to the wide scope of teaching management and involving many departments, in the construction of teaching management information in colleges and universities, the use of teaching management systems lacks overall planning, resulting in the departments that actually use the system are not comprehensive, and can not achieve teaching management departments.

\subsection{Teaching management information system lags behind}

The teaching management information system lags behind, and it is also a weak link in the construction of teaching management information. In the construction of teaching management information, the teaching management system involves a wide range of work and complicated work. In the daily work, the existing teaching management system does not have the relevant provisions of the teaching management information system, and the system development matching the teaching management information is relatively slow. The teaching management information system lags behind, mainly bringing about two aspects. On the one hand, there is no institutional constraint between departments, and it is difficult to guarantee the standardization and standardization of teaching management. On the other hand, the lag of system construction cannot meet the modern teaching management information. The requirements of construction have restricted the efficient operation of the teaching management system. When the staff at all levels of teaching management in colleges and universities carry out specific work, there is no guarantee system related to teaching management information, which is easy to cause chaos in the construction management of teaching management information. In case of problems, the mutual reversal caused by unclear duties happens sometimes.

\subsection{The quality of teaching management personnel is low}

As the practitioners of teaching management activities in colleges and universities, teaching 
management personnel play an important role in the construction of teaching management information. The low quality of teaching management personnel has become a bottleneck in the construction of teaching management information, making it difficult to play its due role in the construction of teaching management information. In the daily teaching management activities, due to the limitations of their own knowledge level, teaching management personnel can only handle texts and reports simply, do not have the application operation ability of teaching management information construction, and face interactive information processing with the teaching management system. At the time, it is impossible to achieve the level of computer operation that teaching management personnel should have. From the overall point of view, the information processing ability of current teaching management personnel is generally lacking, which plagues the implementation of teaching management information construction.

\section{The Strategy of Improving Teaching Management Information Construction}

In order to further improve the level of teaching management information construction, the following three aspects of the strategy can be adopted in view of the above problems in the construction of teaching management information.

\subsection{Improve the awareness of teaching management information}

Improving the awareness of teaching management information is the key to improving the construction of teaching management information. In the process of teaching management information construction, relevant personnel of teaching management information construction should pay attention to the role of teaching management information construction in modern teaching management, strengthen the transformation of educational concepts and ideas, continuously improve the information awareness of teaching management, and attach importance to information. The development of teaching management is crucial to the construction of teaching management information.

For colleges and universities, colleges and universities should change the traditional concept of teaching management, establish the concept of informational teaching management, attach importance to the propaganda of teaching management information, form the consciousness and habit of using information to solve practical problems, and strengthen the ideological change of educational concepts. Create information-based teaching management.

\subsection{Improve the teaching management information system}

Teaching management information system is an important link in the construction of teaching management information, and perfecting the teaching management information system is an effective measure to improve the information management of teaching management.

For the teaching management information system, the construction of teaching management information in colleges and universities should be combined with the actual situation of teaching management in colleges and universities to carry out targeted information of teaching management. In view of the current situation of independent departments, strengthen the system. The compatibility between the two is targeted at the construction of teaching management information, and it is integrated as much as possible to achieve the purpose of collaboration between the various departments of teaching management in teaching management. For systems that cannot be integrated, through the analysis of the data in the system, combined with relevant standards, secondary development is carried out to establish a unified interface with the teaching management system, so that the data can be unified and completed, and the purpose of perfecting the teaching management information system is achieved.

\subsection{Optimize the quality of teaching management personnel}

Optimizing the quality of teaching management personnel is the key and difficult point in the construction of teaching management information. In the construction of teaching management information, improving the information technology level of teaching management personnel is 
conducive to maintaining the normal operation of the information system and optimizing the quality of teaching management personnel. It is necessary to pay full attention to the training of teaching management personnel on information technology and strengthen its information technology.

For teaching management personnel, it is possible to systematically train teaching management personnel in the form of organizing scientific and technological information lectures, improve computer operation ability, improve the information technology quality level of teaching management personnel, improve the use of teaching management system and data. The ability of information collection, analysis and processing makes it more in-depth understanding of the system, familiar with the operation, to ensure the smooth development of teaching management information.

In short, the information of teaching management is an inevitable trend in the development of modern teaching. Teaching management information is a comprehensive systematic project with long-term and complex nature. The construction of teaching management information should be combined with the actual situation of teaching management in colleges and universities, improve the awareness of teaching management information, improve the teaching management information system, improve the teaching management information system, optimize the quality of teaching management personnel, and constantly explore and improve the teaching management information construction. Only in this way can we promote the improvement of the level of information in teaching management, and thus ensure the deepening of higher education reform.

\section{References}

[1] Xiaoli Hu, We Zhang. Reflections on Strengthening Teaching Management in Colleges and Universities [J]. Modern Marketing (College Edition). 2016 (7).

[2] Xiaolan Huang. Some Thoughts on the Reform of Teaching Management in Colleges and Universities [J]. Journal of Guangxi Teachers College (Philosophy and Social Sciences Edition). 2017 (2).

[3] Chunping Ai, Fu Hua. Through multimedia management, multimedia classrooms play a greater role in college teaching [J]. Science and Technology Information. 2015 (16).

[4] Wei Feng. Practice scientific development concept to accelerate the construction of information management in colleges and universities [J]. New West (second half). 2016 (3).

[5] Hongmei Li. Reflections and Explorations on the Construction of Teaching Management Information in Higher Education [J]. Higher Agricultural Education. 2016 (2). 